\title{
EFFECTS OF ISOFLAVONES ON THE SKIN OF POSTMENOPAUSAL WOMEN: A PILOT STUDY
}

\author{
Alfeu Accorsi-Neto, ${ }^{\mathrm{I}}$ Mauro Haidar, ${ }^{\mathrm{I}}$ Ricardo Simões, ${ }^{\mathrm{I}}$ Manuel Simões, ${ }^{\mathrm{II}}$ José \\ Soares-Jr, ${ }^{\mathrm{IIII}}$ Edmund Baracat ${ }^{\mathrm{III}, \mathrm{IV}}$
}

doi: $10.1590 / \mathrm{S} 1807-59322009000600004$

\begin{abstract}
Accorsi-Neto A, Haidar M, Simões R, Simões M, Soares-Jr J, Baracat E. Effects of isoflavones on the skin of postmenopausal women: a pilot study. Clinics. 2009;64(6):505-10.
\end{abstract}

OBJECTIVE: The aim of this study was to evaluate the effects of isoflavones on the skin of postmenopausal women.

DESIGN: A prospective study was performed with 30 postmenopausal women before and immediately after the end of treatment with $100 \mathrm{mg} /$ day of an isoflavones-rich, concentrated soy extract for six months. A skin punch was performed in the gluteal region for sample collection before and immediately after the treatment program. Morphometric determination of epidermal thickness, the papillary index (wrinkling), and the amount of dermal elastic and collagen fibers was assessed. In addition, the number of blood vessels in the sample was also evaluated. The paired Student's t-test was used for statistical analysis $(P \leq 0.05)$.

RESULTS: Isoflavone treatment resulted in a $9.46 \%$ increase in the thickness of the epidermis in 23 patients. In addition, the papillary index was reduced in 21 women. The papillary index was inversely proportional to skin wrinkling, i.e., there were a large number of papillae after treatment. The amount of collagen in the dermis was increased in 25 women ( $86.2 \%$ ). In 22 women $(75.8 \%)$ we observed that the number of elastic fibers increased. The number of dermal blood vessels was significantly increased in 21 women.

CONCLUSION: Our data show that the use of a concentrated, isoflavone-rich soy extract during six consecutive months caused significant increases in epithelial thickness, the number of elastic and collagen fibers, as well as the blood vessels.

KEYWORDS: Isoflavones; Postmenopausal women; Skin; Blood vessels; Collagen fibers.

\section{INTRODUCTION}

Higher socio-economic development and the improvement of quality of life thanks to better medical care has led to a worldwide increase in life expectancy, especially for post-menopausal women. ${ }^{1}$

In this period, many skin alterations are observed that

\footnotetext{
${ }^{\text {I Gynecology Department, Federal University of São Paulo (UNIFESP) - São }}$ Paulo/SP, Brazil.

II Morphology Department, Federal University of São Paulo (UNIFESP) São Paulo/SP, Brazil.

III LIM-58, Laboratório de Ginecologia Estrutural e Molecular, Faculdade de Medicina da Universidade de São Paulo - São Paulo/SP, Brazil.

Iv Disciplina de Ginecologia, Departamento de Obstetrícia e Ginecologia, Faculdade de Medicina da Universidade de São Paulo - São Paulo/SP,Brazil. Study performed at: Gynecology Department of the Federal University of São Paulo (UNIFESP) - São Paulo/SP, Brazil.

Email: jsoares415@hotmail.com

Tel: 5511 5081-3685

Received for publication on January 25, 2009

Accepted for publication on March 02, 2009
}

affect quality of life. Some of these changes seem to be associated mainly with the process of aging and sun exposure; others occur as a consequence of estrogen deficiency. The mechanisms involved seem to originate from the dermal and epidermal reduction of cellularity and collagen quantity and from skin thinning. ${ }^{2-4}$ Brincat et al. ${ }^{5}$ stated that this loss is faster in the initial years after menopause, when it reaches around $2.1 \%$ per year, causing a total cumulative loss of about $30 \%$ of skin thickness in the first five years thereafter.

Skin is the main non-oral communication organ, the largest and one of the most complex in the body. It receives about $9 \%$ of the cardiac output and is involved in absorbing many different substances. It also possesses biochemical functions, such as steroid hormone metabolism, ${ }^{6}$ and can be impacted by certain systemic diseases. ${ }^{7}$

The skin is made up of an epithelial portion of ectodermic origin, the epidermis, and a conjunctive portion of mesodermic origin, the dermis. The epidermis contains 
keratinocytes, which form a keratinized stratified squamous epithelium. Many special types of cells are present in the skin, such as melanocytes, which produce the melanin pigment, Langerhans cells, which are part of the immune system, and Merckel cells, which represent mechanical receptors. The dermis contains a papillar layer, formed by a loose conjunctive tissue, and a reticular layer, formed by a dense non-modeled conjunctive tissue. ${ }^{8}$

Skin not only consists of cells, but also functions as an extracellular space that is often filled by a complex of components constituting the extracellular matrix. Morphologically, the extracellular matrix contains a large number of proteins and glycosaminoglycans, which organize themselves to form a net. Variations in the cellular and matrix quality and quantity, as well as their organization, are responsible for the morphological, functional and pathological diversity of skin tissue. ${ }^{9}$

Collagen and elastin are responsible for the structural and elastic qualities of skin. Collagen represents 70 to $80 \%$ of the dry weight of human skin, being the largest dermal component. It represents $30 \%$ of the total protein content in the human body. ${ }^{5}$

Though a large number of collagen types have been described to date, the most abundant and well-studied types are I, II and III. ${ }^{10}$ Type I accounts for $90 \%$ of the total collagen in the body of a mammal. It is synthesized by fibroblasts and osteoblasts and forms thick and strong fibers. ${ }^{9}$

Fibroblasts exhibit receptors for estrogens and androgens. A decrease in estrogens affects glycosaminoglycans polymerization, which can eventually lead to a decrease in the collagen production rate. ${ }^{10,11}$ Decreased estrogen also causes granular degeneration and fragmentation of elastic fibers together with coalescence of cystic spaces. Under these conditions, a significant decrease in the number of small arterial vessels can be detected in the microcirculation. ${ }^{11}$ As a consequence, thinning of the epidermal layer and the interpapillar cristae in the dermis-epidermis junction occurs. ${ }^{3}$

Current treatment with natural estrogens results in morphological modifications to the aged skin, characterized mainly by an increased number of fibroblasts and glycosaminoglycans. The increase of the latter component suggests an increase in the water molecules of the dermal collagen component. ${ }^{12}$ However; estrogen therapy is not always feasible due to its side effects and contraindications. Therefore, many authors have evaluated the possibility of using phytohormones as an alternative to hormonal therapy after menopause, especially in patients for whom an estrogen treatment is not indicated. ${ }^{13-15}$
Phytoestrogens are nonsteroidal substances of vegetal origin that exhibit agonistic and antagonistic estrogen activities. ${ }^{16,17}$ This behavior arises because they have a heterocyclic phenolic composition with structural similarities to the estrogens. ${ }^{16}$

Isoflavones, particularly genistein, have a higher affinity for the subtype of the estrogen receptor, which is present in bones, skin and the cardiovascular system, as opposed to the subtype, which is found in the uterus and breast. ${ }^{17}$ Some authors have observed that oral intake of $40 \mathrm{mg}$ soy isoflavone aglycones per day improves the aging skin of middle-aged women as compared to a placebo group. ${ }^{18,19}$ In rats, red clover isoflavones are effective in reducing skin aging induced by estrogen deprivation. ${ }^{9}$ However, the effect of isoflavones compared to estrogen on the skin remains unknown.

This study was undertaken to address the scarcity of research to date regarding isoflavone effects on female postmenopausal skin.

\section{MATERIALS AND METHODS}

Thirty postmenopausal patients who attended the Ambulatório de Climatério do Departamento de Ginecologia e Obstetrícia da Faculdade de Medicina de Catanduva (FAMECA)* in the year 2005 were enrolled in our study. The study protocol was approved by the FAMECA Ethics Commission. All patients gave their informed consent prior to participation.

Women older than forty who had experienced amenorrhea for longer than one year and exhibited high circulating levels of gonadotrophins were identified as post-menopausal. ${ }^{1}$ Patients undergoing hormone therapy as well as those with factors that may interfere with the medication were excluded.

In addition to the regular anamnesis and the general physical and gynecological examinations, a skin biopsy was taken. The biopsy was always taken in the gluteal region, in the external superior square with a $4 \mathrm{~mm}$ in extension conducted using rotatory movements, until it reached the hypodermis. After routine processing, the slides were stained by hematoxylin-eosin (HE) to study the thickness of the epidermis; by the Verhoeff stain, to identify elastic fibers; and by picrosirius red, to highlight collagen fibers. An immuno-histochemical procedure using the CD 34 antigen was employed as a blood vessel marker.

The morphometric study consisted of a volumetric analysis that involved point counting to quantify representative areas of collagen and elastic fiber. In order 
to strengthen the results assessment and to maintain the data within confidence intervals, we calculated the volume densities (VD) of the collagen and elastic fibers in a preliminary study involving three histological cuts. We derived this data from the ratio of the number of points reached by each structure $(\mathrm{Pp})$ to the number of test-points $(\mathrm{Tp})$, i.e. $\mathrm{VD}=\mathrm{Pp} / \mathrm{Tp} .{ }^{20}$ After the volume density had been calculated for each structure studied, a nomogram was used for immediate visualization to determine the necessary number of points given a relative standard error of 5\%. ${ }^{21}$ For the volumetric analysis of collagen and elastic fibers, 105 and 3264 points were counted, respectively.

Direct reading was used for vessel counting, without the need for any device assistance. A vascular unit was identified by the presence of hazel colored cells bordering the luminal space. We analyzed ten fields per slide in order to count the number of vessels.

Epidermal thickness and the papillary index were determined by light microscopy with a clear chamber (Leitz), which allowed visualization of the varied structures by means of image superposition. Using a 16x objective and a 10x ocular lens, the epidermal contour was printed on a sheet of paper using a standardized net as described by Merz. ${ }^{19}$ Alternating semi-circles formed sinusoidal parallel lines with equidistant points that were modified to create 100 intersection points.

Epidermal thickness was calculated from the occupied area between the inner contour, which corresponds to the basal layer, and the outer contour of the corneus layer.

The epidermis wrinkling index was considered equivalent to the papillar index, expressed as the ratio of the outer contour line length of the corneus layer to the inner contour of the epidermis basal layer.

\section{Statistical Analysis}

The effects of isoflavone treatment were analyzed using the paired Student's $t$-test; the Pearson's correlation coefficient was also used to study the variables before and after treatment. In subsequent tables and figures, significant differences $(P \leq 0.05)$ are indicated by asterisks. The power calculation was 28 for a $90 \%$ confidence interval.

\section{RESULTS}

Of the 29 studied patients, 23 presented a $9.46 \%$ increase in epidermal thickness $(P<0.01)$. The epithelial thickness averaged $560.8 \pm 4.4 \mu \mathrm{m}$ before and $613 \pm 4.6 \mu \mathrm{m}$ after the six months of treatment (Table 1, Fig. 1). Though the epidermal papillar index (wrinkling) has been reported to decrease in women after concentrated soy extract therapy, we noted an increase in wrinkling of $10.4 \% \pm 1.9 \%$ after therapy with concentrated soy extract. This index was inversely proportional to the number of dermal papillae.

Dermal collagen quantification suggested that 25 women $(86 \%)$ exhibited a significant rise $(7.6 \pm 1.5 \%)$ in the number of collagen fibers after treatment. The values were $152.0 \pm$ 2.2 and $163.0 \pm 2.3$ (no units) before and after therapy with concentrated soy extract, respectively $(P<0.01)$. In 22 of the women $(75.8 \%)$, a $18.8 \pm 4.8 \%(P<0.01)$ increase in number of elastic fibers was detected after treatment. The average values were $525.4 \pm 4.2$ and $611.2 \pm 4.6$ (no units) before and after treatment, respectively. We observed that 21 (72.4\%) women presented a $20.2 \pm 5.9 \%(P<0.01)$ increase in the number of dermal vessels after treatment. The average numbers of vessels were $64.2 \pm 1.4$ and $74.1 \pm 1.6$ before and after treatment, respectively.

Table 1 - histological parameters in postmenopausal skin

\begin{tabular}{lcc}
\hline Parameters & Before treatment & After treatment \\
\hline epithelial thickness $(\mu \mathrm{m})$ & $560.8 \pm 4.4$ & $613 \pm 4.6^{*}$ \\
epidermal papillar index $(\%)$ & $10.4 \pm 1.9$ & $14.7 \pm 4.0^{*}$ \\
dermal collagen (no units) & $152.0 \pm 2.2$ & $163.0 \pm 2.3^{*}$ \\
elastic fibers (no units) & $525.4 \pm 4.2$ & $611.2 \pm 4.6^{*}$ \\
dermal vessels (number per slide) & $64.2 \pm 1.4$ & $1.1 \pm 1.6^{*}$ \\
\hline
\end{tabular}

${ }^{*} \mathrm{p}<0.01$ compared to data before treatment - paired Student's t-test.

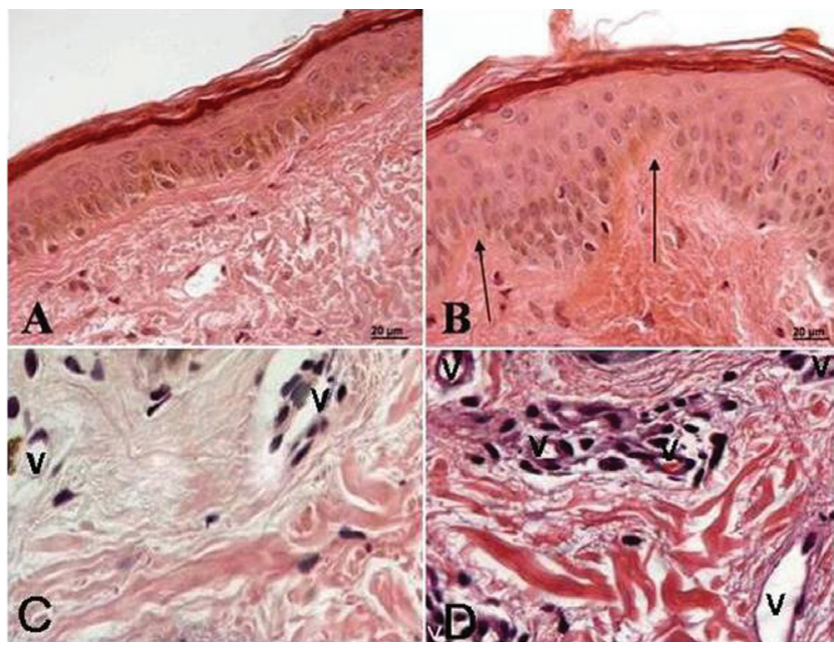

Figure 1 - Photomicrograph of a histological gluteal skin section from a patient before $(\mathrm{A}, \mathrm{C})$ and after $(\mathrm{B}, \mathrm{D})$ treatment with isoflavones. A - Note the absence of the dermal papilae and a thin epidermal layer. B - Note the increased epidermal thickness. C and D - Note the blood vessels. The arrows indicate the dermal papillae, and " $v$ " are the vessels. (A and B 250x; C and D 450x, H.E.)

\section{DISCUSSION}

Postmenopause is characterized by several changes due to a physiological reduction in the ovarian production of 
steroidal hormones. ${ }^{22-24}$ This creates a hypoestrogen state that can provoke significant phenomena such as hot flashes, decreased libido, loss of bone mass and atrophy of the genitourinary tract and skin. ${ }^{17}$

Following the Raine-Fenning et al. ${ }^{25}$ study, several authors identified a progressive decrease in dermal collagen concentrations, skin drying and even skin atrophy after menopause. We note that these latter phenomena, related to the drop in circulating estrogens, manifest in a number of ways. In some postmenopausal women the changes occur slowly, but in others the onset can be very fast. ${ }^{26}$

To eliminate or at least minimize the deleterious effects of estrogen deficiency, estrogen therapy is not only directed at the early symptoms (hot flashes) but also aims to arrest certain well-known menopausal conditions such as osteoporosis and skin atrophy. ${ }^{11,27}$ Data in the literature has shown that long-term estrogen treatment is effective in increasing skin thickness in postmenopausal women. ${ }^{15,28,29}$

Despite the known beneficial effects of hormonal therapy, compliance rates are low, ranging from 10 to $30 \% .{ }^{17,30}$ Given this fact, alternative therapeutic options are required for women who do not accept or who have some contraindication to classical hormonal therapy in the postmenopausal period. Of the available alternatives, phytoestrogens (especially isoflavones) are often highlighted, with particular emphasis on concentrated, isoflavone-rich soy extracts.

Isoflavones appear to exhibit biological activities similar to estrogen because they are heterocyclic phenolic compounds with structural similarities to both natural and synthetic estrogens. ${ }^{31-33}$

Certain authors have reported that isoflavone effects depend on the plasma concentrations of their corresponding aglycones, such as genistein and daidzein. ${ }^{34}$ In addition, we note that the metabolites of these substances may also exhibit biological activity. Among these, equol, the final product of daidzein biotransformation, has clear estrogen-like activity and displays affinity for both the and estrogen receptors. Also, it is superior to other isoflavones with regards to antioxidant activity. ${ }^{35}$

Cai and $\mathrm{Wei}^{36}$ have demonstrated that ingesting soy isoflavone (genistein) for 30 days significantly increases the activity of the antioxidant enzyme superoxide dismutase in various mouse organs. The largest increases of antioxidant enzyme activity were observed in the intestine and on the skin.

Many studies have shown that isoflavones may impact the skin. ${ }^{37,38}$ The results presented herein show an increase in the epidermal and dermal skin thickness after a sixmonth treatment program with a concentrated soy extract at a dose of $100 \mathrm{mg}$ per day. In addition to an increase in the epidermal thickness, we also found increases in the papillary index, quantity of collagen and elastic fibers, and number of dermal vessels.

Kotsopoulos et al. ${ }^{37}$ conducted a double-blind, placebocontrolled study involving 94 postmenopausal women aged 50 to 75 years. They each received an isoflavone-enriched high-protein diet. The study reported an enhancement in the moisture content of facial skin, with a significant decrease in drying after three months of treatment. By contrast, Tomaszewski et al. ${ }^{38}$ evaluated human skin fibroblasts in cell culture, and reported an increase in collagen production after treatment with isoflavones, although this effect was less than that induced by estrogen.

Despite minimal evidence supporting isoflavone action on skin, there are reports that genistein may exert protective effects on aging skin as well as reducing the risk of skin carcinoma induced by ultraviolet irradiation, an effect presumably related to the inhibition of dermal tyrosine kinases in animals. ${ }^{39}$ However, there is inconsistent evidence that this would happen in menopausal women. ${ }^{37}$

The effect of estrogens on the thickness of the skin epithelial layer is well understood. Fuchs et al. ${ }^{29}$ reported a $23 \%$ increase in epithelium thickness after six months of treatment with topical estrogens. In animals, Calil et al. ${ }^{40}$ have shown that treatment with equine conjugated estrogens increases the epithelial thickness of the skin of adult ovariectomized mice. Accordingly, isoflavones should improve the skin epithelium (thickness and papillar index) by binding to estrogen receptors, thereby promoting cellular proliferation. ${ }^{41}$

Besides epithelial cells, estrogen receptors are found in other skin components such as in fibroblasts. In these cells, estrogens act by reducing metalloprotease activity in the skin. Therefore, this should result in less degradation of skin collagen fibers during estrogen treatments. ${ }^{42} \mathrm{We}$ emphasize that collagen is responsible for both skin structure and strength. In addition, estrogenic action enhances the concentration of glycosaminoglycans, thus elevating skin water content and consequently increasing skin turgor. ${ }^{43}$ Our results suggest an increase in the number of skin elastic and collagen fibers. This effect would presumably be mediated by the activation of the estrogen receptor, although the exact subtype that is activated cannot be defined at present.

Many clinical studies in postmenopausal women suggest that skin thickness is greater in those who have been treated with estrogens than in those who have not. This effect is more evident after at least one year of treatment, ${ }^{44,45}$ although this effect has also been shown with much shorter treatment durations. ${ }^{44}$ Conceivably, the increase in collagen content after treatment with concentrated soy extract could be explained by an estrogen-like action of isoflavones. 
As reported elsewhere, skin aging is not totally dependent on estrogen. Many other factors such as ultraviolet radiation (UV) can accelerate the degradation of skin components and the apoptosis of both epithelial and dermal cells..$^{45}$

In animals, treatment with isoflavones offers protection against the initiation and promotion of photocarcinogens in the skin induced by UV radiation. ${ }^{37,46,47}$ Besides this, topical application of genistein can protect against the erythremia caused by UV radiation in humans. ${ }^{39}$ The mechanism of action of isoflavones on skin may not only be dependent on an estrogen-like mechanism, but might also involve the participation of antioxidants. ${ }^{39}$

Skin hydration depends on both the number of vessels and their responsiveness. In postmenopausal patients, the skin tends to progressively dry out and subcutaneous capillaries disappear. Though estrogens increase the concentrations of epidermal and vascular-endothelial growing factors, estrogenic therapy is unable to restore the cutaneous microvasculature after six months of treatment. ${ }^{48}$ Skin vessel maintenance/growth mechanisms are probably related to a complex array of cellular factors, some of which may be independent of the estrogen receptor.

Finally, our data have shown that the administration of a concentrated soy extract for six months can provide definite benefits. We note improvements in skin health for the postmenopausal women in our study, mainly through increased epithelium thickness, elevated concentrations of collagen and elastic fibers, and an increased number of subcutaneous vessels. Presumably, these same effects could also protect skin against the deleterious effects of UV radiation. Isoflavone therapy is worthy of further investigation and should be compared to results obtained in the treatment of postmenopausal women with a standard replacement estrogenic therapy.

\section{REFERENCES}

1. Speroff L, Fritz MA. Clinical gynecologic endocrinology and infertility $7^{\text {th }}$ ed. Lippincott Williams \& Wilkins;2005. p.17-23.

2. Neerken S, Lucassen GW, Bisschop MA, Lenderink E, Nuijs TA. Characterization of age-related effects in human skin: A comparative study that applies confocal laser scanning microscopy and optical coherence tomography. J Biomed Opt. 2004;9:274-81.

3. Gilhar A, Ullmann Y, Karry R, Shalaginov R, Assy B, Serafimovich $\mathrm{S}$, et al. Ageing of human epidermis: the role of apoptosis, Fas and telomerase. Br J Dermatol. 2004;150:56-63.

4. Patriarca MT, Goldman KZ, Dos Santos JM, Petri V, Simoes RS, Soares $\mathrm{JM} \mathrm{Jr}$, et al. Effects of topical estradiol on the facial skin collagen of postmenopausal women under oral hormone therapy: A pilot study. Eur J Obstet Gynecol Reprod Biol. 2007;130:202-5.

5. Brincat MP, Baron YM, Galea R. Estrogens and the skin. Climacteric. 2005; 8:110-23.

6. Reed MJ, Purohit A, Woo LW, Newman SP, Potter BV. Steroid sulfatase: molecular biology, regulation, and inhibition. Endocr Rev. 2005;26:171202.

7. Kleyn CE, Lai-Cheong JE, Bell HK. Cutaneous manifestations of internal malignancy: diagnosis and management. Am J Clin Dermatol. 2006;7:71-84.

8. Prost-Squarcioni C. Histology of skin and hair follicle. Med Sci. 2006;22:131-7.

9. Wulf HC, Sandby-Moller J, Kobayasi T, Gniadecki R. Skin aging and natural photoprotection. Micron. 2004;35:185-91.

10. Varani J, Dame MK, Rittie L, Fligiel SE, Kang S, Fisher GJ, et al. Decreased collagen production in chronologically aged skin: roles of age-dependent alteration in fibroblast function and defective mechanical stimulation. Am J Pathol. 2006;168:1861-8.
11. Hall G, Phillips TJ. Estrogen and skin: the effects of estrogen, menopause, and hormone replacement therapy on the skin. J Am Acad Dermatol. 2005;53:555-68.

12. Son ED, Lee JY, Lee S, Kim MS, Lee BG, Chang IS, et al. Topical application of 17 beta-estradiol increases extracellular matrix protein synthesis by stimulating tgf-Beta signaling in aged human skin in vivo. J Invest Dermatol. 2005; 124:1149-61.

13. Han KK, Soares JM Jr, Haidar MA, de Lima GR, Baracat EC. Benefits of soy isoflavone therapeutic regimen on menopausal symptoms. Obstet Gynecol. 2002;99:389-94.

14. Kaari C, Haidar MA, Soares Jr JM, Nunes MG, Quadros LG, Kemp C et al. Randomized clinical trial comparing conjugated equine estrogens and isoflavones in postmenopausal women: a pilot study. Maturitas. 2006;53:49-58.

15. Verdier-Sevrain S, Bonte F, Gilchrest B. Biology of estrogens in skin: implications for skin aging. Exp Dermatol. 2006;15:83-94.

16. Montani C, Penza M, Jeremic M, Biasiotto G, La Sala G, De Felici M, et al. Genistein is an efficient estrogen in the whole-body throughout mouse development. Toxicol Sci. 2008;103:57-67.

17. Nachtigall LE. Isoflavones in the management of menopause. $\mathrm{J} \mathrm{Br}$ Menopause Soc. 2001;S1:8-11.

18. Izumi T, Saito M, Obata A, Masayuki AR, Yamaguchi H, Matsuyama A. Oral intake of soy isoflavone aglycone improves the aged skin of adult women. J.Nutr Sci Vitaminol 53 2007;53:57-62.

19. Circosta C, De Pasquale R, Palumbo DR, Sampieri S, Occhiuto F. Effects of isoflavones from red clover (Trifolium pretense) on skin changes induced by ovariectomy in rats. Phitother Res. 2006;20:1096-99.

20. Weibel ER, Kistler GS, Scherle WF. Practical stereological methods for morphometrics cytology. J Cell Biol. 1966;30:23-38. 
21. Mandarim-de-Lacerda CA. Morphologic aspects of the left ventricular remodeling in hypertensive cardiomyopathy. Arq Bras Cardiol. 1995;65:523-7.

22. Castelo-Branco C, Rostro F. Management of menopause. Minerva Ginecol. 2006;58:137-52.

23. Maturana MA, Irigoyen MC, Spritzer PM. Menopause, estrogens, and endothelial dysfunction: current concepts. Clinics. 2007;62:77-86.

24. Bonduki CE, Lourenço DM, Motta EL, Soares Jr JM, Haidar MA, Baracat EC. Effect of estrogen-progestin hormonal replacement therapy on blood coagulation and fibrinolysis in postmenopausal women. Clinics. 2007;62:553-60.

25. Raine-Fenning NJ, Brincat MP, Muscat-Baron Y. Skin aging and menopause: implications for treatment. Am J Clin Dermatol. $2003 ; 4: 371-8$

26. Hodis HN. Assessing benefits and risks of hormone therapy in 2008 new evidence, especially with regard to the heart. Cleve Clin J Med. 2008;75 Suppl 4:S3-12.

27. Chedraui P, San Miguel G, Hidalgo L, Morocho N, Ross S. Effect of Trifolium pratense-derived isoflavones on the lipid profile of postmenopausal women with increased body mass index. Gynecol Endocrinol. 2008;24:620-4

28. Sator PG, Schmidt JB, Sator MO, Huber JC, Honigsmann H. The influence of hormone replacement therapy on skin ageing: a pilot study. Maturitas. 2001; 39:43-55

29. Fuchs KO, Solis O, Tapawan R, Paranjpe J. The effects of an estrogen and glycolic acid cream on the facial skin of postmenopausal women: a randomized histologic study. Cutis. 2003;71:481-8.

30. Manson JE, Bassuk SS, Harman SM, Brinton EA, Cedars MI, Lobo R, et al. Postmenopausal hormone therapy: new questions and the case for new clinical trials. Menopause. 2006;13:139-47.

31. Moutsatsou P. The spectrum of phytoestrogens in nature: our knowledge is expanding. Hormones (Athens). 2007;6:173-93

32. Chiechi LM. Dietary phytoestrogens in the prevention of long-term postmenopausal diseases. Int J Gynaecol Obstet. 1999;67:39-40.

33. Mosquette R, Simões MJ, Guerreiro da Silva IDC, Oshima CTF Oliveira-Filho RM, Haidar MA, et al. The effects of soy extract on the uterus of castrated adult rats. Maturitas. 2007;20:173-83.

34. Setchell KD, Brown NM, Desai P, Zimmer-Nechemias L, Wolfe BE, Brashear WT, et al. Bioavailability of pure isoflavones in healthy humans and analysis of commercial soy isoflavone supplements. J Nutr. 2001;131(4 Suppl):1362S-75S

35. Setchell KD, Clerici C, Lephart ED, Cole SJ, Heenan C, Castellani D, et al. S-equol, a potent ligand for estrogen receptor beta, is the exclusive enantiomeric form of the soy isoflavone metabolite produced by human intestinal bacterial flora. Am J Clin Nutr. 2005;81:1072-9.
36. Cai Q, Wei H. Effect of dietary genistein on antioxidant enzyme activities in SENCAR mice. Nutr Cancer. 1996;25:1-7.

37. Kotsopoulos D, Dalais FS, Liang YL, McGrath BP, Teede HJ. The effects of soy protein containing phytoestrogens on menopausal symptoms in postmenopausal women. Climacteric. 2000;3:161-7.

38. Tomaszewski J, Adamiak A, Skorupski P, Rzeski W, Rechberger T. Effect of 17 beta-estradiol and phytoestrogen daidzein on the proliferation of pubocervical fascia and skin fibroblasts derived from women suffering from stress urinary incontinence. Ginekol Pol. 2003;74:1410-4.

39. Huang ZR, Hung CF, Lin YK, Fang JY. In vitro and in vivo evaluation of topical delivery and potential dermal use of soy isoflavones genistein and daidzein. Int J Pharm. 2008:364:36-44.

40. Calil M, Simões MJ, Baracat EC, Haidar MA, Soares Jr JM. Collagen changes after hormonal replacement and tamoxifen in skin of oophorectomized adult rat. Climacteric, Estados Unidos. 2, n.11, p.199.

41. Kwon OS, Han JH, Yoo HG, Lee SR, Kim KH, Eun HC, et al. Expression of androgen receptor, estrogen receptor alpha and beta in the dermal papilla of human hair follicles in vivo. J Dermatol Sci. 2004;36:1769.

42. Kanda N, Watanabe S. Regulatory roles of sex hormones in cutaneous biology and immunology. J Dermatol Sci. 2005;38:1-7.

43. Shah MG, Maibach HI. Estrogen and skin. An overview. Am J Clin Dermatol. 2001;2:143-50.

44. Maheux R, Naud F, Rioux M, Grenier R, Lemay A, Guy J, et al. A randomized, double-blind, placebo-controlled study on the effect of conjugated estrogens on skin thickness. Am J Obstet Gynecol. 1994;170:642-9.

45. Brincat MP. Hormone replacement therapy and the skin. Maturitas. 2000; 35:107-17.

46. Sauerbronn AV, Fonseca AM, Bagnoli VR, Saldiva PH, Pinotti JA. The effects of systemic hormonal replacement therapy on the skin of postmenopausal women. Int J Gynaecol Obstet. 2000;68:35-41.

47. Widyarini S, Spinks N, Reeve VE. Protective effect of isoflavone derivative against photocarcinogenesis in a mouse model. Redox Rep. 2000;5:156-8

48. Chabbert-Buffet N, Bonnin P, Levy B, Abdoucheli-Baudot N, Tribout L, Gaitz JP, et al. Cutaneous microvascular effects of mid-term hormone replacement therapy in healthy postmenopausal women: a prospective placebo controlled trial. J Mal Vasc. 2003;28:190-3. 